\title{
Electoral Rule Disproportionality and Platform Polarization
}

\author{
Konstantinos Matakos* $^{*}$ Orestis Troumpounis ${ }^{\dagger} \quad$ Dimitrios Xefteris $^{*}$
}

October 16, 2015

*King's College London, Department of Political Economy, Strand Room S.2.43, London WC2R 2LS, United Kingdom; e-mail: konstantinos.matakos@kcl.ac.uk

${ }^{\dagger}$ Department of Economics, Lancaster University, The Management School, Bailrigg, LA1 4YX, United Kingdom, e-mail: o.troumpounis@lancaster.ac.uk

${ }_{\ddagger}^{\ddagger}$ Department of Economics, University of Cyprus, PO Box 20537, 1678 Nicosia, Cyprus, e-mail: xefteris.dimitrios@ucy.ac.cy

§Authors' names are intentionally ordered alphabetically. The original idea was Xefteris'. We are grateful to three referees and the editor for their recommendations. Troumpounis acknowledges financial support from the Spanish Ministry of Economy and Competitiveness through grant ECO2012-34581. 


\begin{abstract}
Despite common perception, existing theoretical literature lacks a complete formal argument regarding the relationship between the electoral rule disproportionality and platform polarization. In this paper, we build a model that incorporates the disproportionality of the electoral system in a standard Downsian electoral competition setup with mainly, but not necessarily purely, policy-motivated parties. We first show that in equilibrium, platform polarization is decreasing in the level of the electoral rule disproportionality. We then argue that the number of parties has a positive effect on platform polarization when polarization is measured by the distance between the two most distant platforms. This effect does not hold when polarization is measured by the widely used Dalton index. Constructing a dataset covering more than 300 elections, our main theoretical findings are empirically supported, pointing towards the electoral rule disproportionality as a major determinant of polarization.
\end{abstract}

Keywords: proportional representation; disproportional electoral systems; polarization; policy-motivated parties; number of parties; Duvergerian predictions

The data, code, and any additional materials required to replicate all analyses in this article are available on the American Journal of Political Science Dataverse within the Harvard Dataverse Network at http://dx.doi.org/10.7910/DVN/OX5CZF. 
Party-system polarization has a significant effect on a wide array of policy issues, ranging from the political stability (Sartori 1976) and cabinet survival (Warwick 1994) to the effectiveness of policy making (Tsebelis 2002) and political representation (Abney, Morrison, and Stradiotto 2007; Huber and Powell 1994). Additionally, polarization may have a strong negative effect on economic performance and growth (Frye 2002) and increase the risk of social tension and violent conflict within and between nation states (Esteban and Schneider 2008). Among several alternative theories proposed, one can attribute polarization to a wide range of forces spanning from informational or media-related factors (e.g., DellaVigna and Kaplan 2007; Grosser and Palfrey 2013) to candidates' differing policy preferences (e.g., Calvert 1985; Roemer 1994).

In this paper, we focus on one institutional and one structural determinant of polarization and ask the following questions: How does the electoral rule disproportionality determine the polarization of a party-system when parties are mainly, but not necessarily purely, policy motivated ${ }^{1}$ How does the nature of political competition and the number of competing parties affect polarization? Finally, does empirical evidence support the predictions of the theory?

In light of contradicting empirical results regarding the effect of the electoral rule disproportionality on platform polarization (e.g., Andrews and Money 2009; Budge and McDonald 2006; Calvo and Hellwig 2011; Curini and Hino 2012; Dalton 2008; Dow 2011, 2001; Ezrow 2008), the development of robust theoretical predictions becomes extremely relevant. In the first part of this paper, we do precisely this: We incorporate the electoral rule disproportionality in a Downsian setup and develop two distinct theoretical predictions. We show the existence of a unique equilibrium in which the degree of platform polarization is a) decreasing in the level of electoral rule disproportionality, independently of how polarization is measured, and b) increasing in the number of competing parties ${ }^{1}$ In the main text, we present our results considering only policy-motivated parties. In the online appendix, we show that our results are robust to partially office-motivated parties. 
when polarization is measured by the distance between the two most distant platforms (MDP). If, instead, polarization is measured by the extensively used Dalton index (DI), we argue that the effect of the number of competing parties on platform polarization is nontrivial. In the second part of the paper, we provide empirical evidence in support of these theoretical findings.

The relationship between electoral rules and platform polarization has previously been explored. In his seminal work Cox (1990) analyzed a model with purely office-motivated parties and argued in favor of a negative link between the disproportionality of the electoral rule and platform polarization. More recently, Calvo and Hellwig (2011) applied an alternative approach based on a probabilistic voting model (a là Adams, Merrill, and Grofman 2005), which also led to formal arguments in favor of the negative relationship between the electoral rule disproportionality and platform polarization. Using a citizen-candidate model, Iaryczower and Mattozzi (2013) show that certain equilibria of a proportional system lead to larger polarization than certain equilibria of plurality rule elections.

We believe that the features of an equilibrium of a formal model can better support an empirically testable hypothesis if this equilibrium meets three criteria: a) the equilibrium is proven to exist, b) it is essentially unique, and c) it relies on standard assumptions regarding the interests of all participating agents (both parties and voters). To our knowledge, the present formal analysis is the first to combine all three of these features.

Cox (1990) stresses that his "results only tell what will happen if there is an equilibrium; they do not guarantee that an equilibrium will exist." In contrast, the approach taken by Calvo and Hellwig (2011) neatly guarantees equilibrium existence. Nevertheless, this is achieved by introducing a non-conventional assumption on voters' preferences: Voters not only care about parties' proposed platforms, but also care about the asymmetry between a party's seat and vote share. Finally, given the nature of the citizen-candidate model employed, Iaryczower and Mattozzi (2013) cannot provide straightforward comparisons across electoral systems due to the well-known problem of multiplicity of equilibria 
(for further discussion see Dhillon and Lockwood 2002).

Our work overcomes the complexities of establishing the existence of an equilibrium in a framework with standard voters' preferences by introducing policy-motivated parties (a là Calvert 1985; Wittman 1977). Given the unique equilibrium prediction obtained, we are able to explore and empirically test the link between the electoral rule disproportionality and platform polarization. The way we overcome the problems of possible non-existence of equilibria is not novel in the literature. Groseclose (2001), for example, used this framework to deal with the non-existence of pure strategy equilibria in a competition between two office-motivated candidates of unequal valence.

A common link between our paper and the aforementioned literature (Calvo and Hellwig 2011; Cox 1990; Iaryczower and Mattozzi 2013) is the analysis of a continuum of disproportionalities. In essence, our analysis considers any rule that lies between a purely proportional and a winner-takes-all electoral rule. This continuum not only allows the analysis of different electoral systems in an abstract way but also permits the comparison of different electoral rules that may belong in the same family despite varying disproportionality. For example, considering proportional representation (PR) systems, Italy's electoral rule is much more disproportional compared to the Netherlands'. ${ }^{2}$

In order to fully grasp why electoral disproportionality acts as a centripetal force, thereby resulting in low levels of polarization, we first model a two-party election. Let

\footnotetext{
${ }^{2}$ For important pairwise comparisons between first past the post (FPTP) and proportional systems, see Austen-Smith (2000); Becher (2014); Funk and Gathmann (2013); Iversen and Soskice (2006); Lizzeri and Persico (2001) on redistribution, Morelli (2004) on party formation, and Persson, Tabellini, and Trebbi (2003) on corruption. For a pairwise comparison between plurality and runoff elections, see Osborne and Slivinski (1996). Myerson (1993a,b) offer pairwise comparisons between PR, approval voting, FPTP, and the Borda rule, focusing on the issues of corruption and campaign promises. A recent series of papers by Dellis and Oak (2015, 2007); Dellis (2013) also focuses on interesting pairwise comparisons.
} 
the leftist party have its preferred policy somewhere to the left of the ideal policy of the median voter while the rightist party has its preferred policy somewhere to the right of the ideal policy of the median voter. First, parties announce their platforms. Second, voters observe the announced platforms and vote for the party that proposed the platform closest to their ideal policy. A policy is then implemented according to the parliamentarymean model (De Sinopoli and Iannantuoni 2007; Llavador 2006; Merrill and Adams 2007; Ortuño-Ortín 1997). ${ }^{3}$ In such a model, the implemented policy is a weighted average of parties' announced platforms where parties' weights are determined by their parliamentary power. The parliamentary-mean model therefore represents a model of consensual democracies (Lijphart 1984). The level of inclusiveness of the policy setting process will clearly depend on the disproportionality of the electoral system. As common in these models, parties choose to differentiate in equilibrium, and this heterogeneous behavior is obtained without needing to assume that parties are uncertain about voters' preferences. This is in contrast to other important contributions with policy-motivated parties (e.g., Calvert 1985; Groseclose 2001; Wittman 1977) where the presence of such uncertainty is

${ }^{3}$ We borrow the model's name from Merrill and Adams (2007) who compare it to the dominant-party model where each party implements its proposed platform with probability equal to its vote (or seat) share (Merrill and Adams 2007; Faravelli and Sanchez-Pages 2014; Iaryczower and Mattozzi 2013). We will further interpret our results through the dominant-party model at a later stage.

For two-party compromise models under PR elections, see Llavador (2006); OrtuñoOrtín (1997). For multi-party models, see De Sinopoli and Iannantuoni (2007, 2008); Gerber and Ortuño-Ortín (1998); Merrill and Adams (2007). An alternative to assuming such policy compromise in PR elections would involve the analysis of post-electoral bargaining and coalition formations (Austen-Smith 2000; Austen-Smith and Banks 1988; Baron and Diermeier 2001; Baron, Diermeier, and Fong 2012; Cho 2014; Indridason 2011). Although the interest of such models is indisputable, their applicability in a comparative analysis of different electoral is problematic. 
crucial.

Our theoretical results identify disproportional electoral rules as a major centripetal force. The intuition behind this is clear. On one hand, as a party moves towards the center, it increases its vote share and, hence, its weight in the implemented policy. On the other hand, when the leftist (rightist) party becomes too moderate in comparison to its opponent, the implemented policy might end up too far to the right (left), if the extra seat share gained from this moderation is relatively small. As the disproportionality of the electoral system increases, proposing a moderate platform may be worthwhile since the incentives to obtain some extra votes are amplified. In highly disproportional systems, a small advantage in votes is translated into a large advantage in parliamentary seats, and hence, into a large asymmetry between the weights of the two parties in the implemented policy. This result generates the first empirically testable hypothesis of our model: An increase in the electoral rule disproportionality decreases platform polarization.

We conduct the same analysis introducing a third party. ${ }^{4}$ We show that in equilibrium platform polarization measured by the MDP moves in the same direction as in the twoparty election (higher electoral rule disproportionality leads to less platform polarization). Moreover, ceteris paribus and under an MDP measure, a larger number of competing parties increases platform polarization. On the other hand, our analysis shows that the Dalton index (DI) does not provide a global prediction regarding the effect of the number

${ }^{4}$ In order to keep our analysis to a reasonable length, we do not allow the number of parties to depend on the electoral rule disproportionality. In the working paper version of our work (Matakos et al. 2013), we nevertheless consider a variation of this model with an endogenous number of parties that includes an entry stage in the game. We show that in line with the Duvergerian predictions (Duverger 1954), the number of competing parties is decreasing in the level of electoral rule disproportionality. Our results, therefore, point at a second indirect channel through which disproportionality affects polarization: As the number of parties decreases in the level of electoral rule disproportionality, the centripetal forces of disproportionality are further amplified. 
of parties on the degree of platform polarization.

Our empirical analysis departs from recent research in terms of the estimation methodology and survey design in the following aspects. First, by combining three data sources (Comparative Political Data Set I, Comparative Manifesto Project, and Carey and Hix 2011), we construct a balanced panel of 23 advanced democracies (OECD states) with a large number of electoral observations over a 50-year period. This totals more than 300 observations. Second, our study simultaneously considers a) both continuous and categorical measures of the electoral rule (dis)proportionality, b) two different measures of platform polarization (the MDP and the DI as detailed above), and c) random and fixed effects estimators. Our empirical findings provide strong support in favor of our main theoretical prediction: The level of platform polarization is decreasing in the level of electoral disproportionality. Furthermore, as our theory predicts, the number of competing parties has a significant positive impact on platform polarization when the latter is measured by the MDP.

\section{The Model}

We construct a formal model in line with the parliamentary-mean model (e.g., Casamatta and De Donder 2005; De Sinopoli and Iannantuoni 2007; Llavador 2006; Merrill and Adams 2007; Ortuño-Ortín 1997). In contrast with past models, our model allows the implemented policy to not only depend on parties' vote shares and proposed platforms, but also on the disproportionality of the electoral system. We first consider a two-party election $(j=L, R)$ where parties strategically announce their platforms. Voters observe these platforms and vote for one of the two parties. Given parties' vote shares $\left(V_{L}\right.$ and $\left.V_{R}\right)$, the announced platforms $\left(p_{L}\right.$ and $\left.p_{R}\right)$, and the (dis)proportionality of the electoral system $(n)$, a policy $\hat{p}$ is implemented.

The policy space is assumed to be continuous, one-dimensional, and represented by the interval $\Pi=[0,1]$. There is a unit mass of voters whose ideal policies are distributed 
across the policy space according to a continuous and twice-differentiable probability measure $F$ on $\Pi$ with median $m$ (i.e., $F(m)=\frac{1}{2}$ ). Let $\pi_{i} \in \Pi$ denote the ideal policy of individual $i$. We assume that each voter cares about the remoteness (but not the direction) of the proposed platform $p_{j}$ from his ideal policy $\pi_{i}$. Formally, a voter $i$ with ideal policy $\pi_{i}$ votes for party $j$ if $\left|p_{j}-\pi_{i}\right|<\left|p_{-j}-\pi_{i}\right|$ and votes for either of the two parties with equal probability if he is indifferent between the two (i.e. when $\left|p_{j}-\pi_{i}\right|=\left|p_{-j}-\pi_{i}\right|$ ). We denote as $\bar{\pi}$ the ideal policy of the indifferent voter. That is, $\bar{\pi}$ is the ideal policy of the voter for whom it holds that $\left|p_{L}-\bar{\pi}\right|=\left|p_{R}-\bar{\pi}\right|$. Given that preferences are symmetric, the location of the indifferent voter is always halfway between the platforms proposed by the two parties. Formally, $\bar{\pi}=\left(p_{L}+p_{R}\right) / 2$, and, therefore, parties' vote shares are given by

$$
V_{L}\left(p_{L}, p_{R}\right)= \begin{cases}F(\bar{\pi})=F\left(\frac{p_{L}+p_{R}}{2}\right), & \text { if } p_{L}<p_{R} \\ \frac{1}{2}, & \text { if } p_{L}=p_{R} \\ 1-F(\bar{\pi})=1-F\left(\frac{p_{L}+p_{R}}{2}\right), & \text { if } p_{L}>p_{R}\end{cases}
$$

and

$$
V_{R}\left(p_{L}, p_{R}\right)=1-V_{L}\left(p_{L}, p_{R}\right)
$$

Parties are policy motivated. Their payoffs depend on the implemented policy rather than on an exogenously given office value for winning the election. ${ }^{5}$ Each party $j$ has an ideal policy $\pi_{j} \in \Pi$ and $\pi_{L}<m<\pi_{R}$. Party $j$ 's payoffs when policy $\hat{p}$ is implemented are given by $U_{j}(\hat{p})=v\left(\left|\hat{p}-\pi_{j}\right|\right)$, where $v:[0,1] \rightarrow \mathbb{R}$ is any twice differentiable strictly decreasing function.

The implemented policy is a function of parties' parliamentary power and parties' proposed platforms $\left(p_{L}, p_{R}\right)$. Parties' seat shares $\left(S_{L}, S_{R}\right)$ are a function of parties' vote shares $\left(V_{L}, V_{R}\right)$ and the disproportionality of the electoral system denoted by $n$. We

\footnotetext{
${ }^{5}$ In the online appendix, we relax this assumption by allowing parties to be partially office motivated, and we show that our main predictions remain unaffected.
} 
formally define the implemented policy function as the following:

$$
\hat{p}\left(p_{L}, p_{R}, n\right)=S_{L}\left(p_{L}, p_{R}, n\right) \times p_{L}+S_{R}\left(p_{L}, p_{R}, n\right) \times p_{R}
$$

This function captures the post-electoral compromise between parties' platforms depending on parties' parliamentary power. Parties' vote shares are translated into parliamentary seat shares depending on the electoral rule disproportionality $n$ following Theil $(1969):^{6}$

$$
\frac{S_{L}}{S_{R}}=\left(\frac{V_{L}}{V_{R}}\right)^{n}
$$

When $n=1$, the above formula captures a purely proportional representation system. Letting $n=3$ the allocation of seats follows the famous "cube law", which is considered a good approximation of the distortions created in favor of the winner in FPTP elections. In general, as $n$ increases, the electoral system more disproportionately favors the winner of the election. In order to apply the term disproportionality as it is conventionally understood - that is, in favor of the winner - we assume throughout the paper that $n \geqslant 1$.

Since we know that $S_{L}+S_{R}=1$ and that $S_{L} / S_{R}=\left(V_{L} / V_{R}\right)^{n}$, we can rewrite the seat shares as follows: $S_{L}=V_{L}^{n} /\left(V_{L}^{n}+V_{R}^{n}\right)$ and $S_{R}=V_{R}^{n} /\left(V_{L}^{n}+V_{R}^{n}\right)$. Therefore, the implemented policy function can be rewritten:

$$
\hat{p}\left(p_{L}, p_{R}, n\right)=\frac{V_{L}\left(p_{L}, p_{R}\right)^{n}}{V_{L}\left(p_{L}, p_{R}\right)^{n}+V_{R}\left(p_{L}, p_{R}\right)^{n}} p_{L}+\frac{V_{R}\left(p_{L}, p_{R}\right)^{n}}{V_{L}\left(p_{L}, p_{R}\right)^{n}+V_{R}\left(p_{L}, p_{R}\right)^{n}} p_{R}
$$

${ }^{6}$ Taagepera (1986) offers a further analysis of the above formula, as well as empirical estimations of parameter $n$. For an overview of measures of bias and the proportionality in the relationship between vote shares and seat shares, see Grofman (1983). Gallagher (1991) provides an analysis of indices and empirical measures of disproportionality. For recent applications of this formula, see Calvo and Hellwig (2011); Ergun (2013); King (1990). 


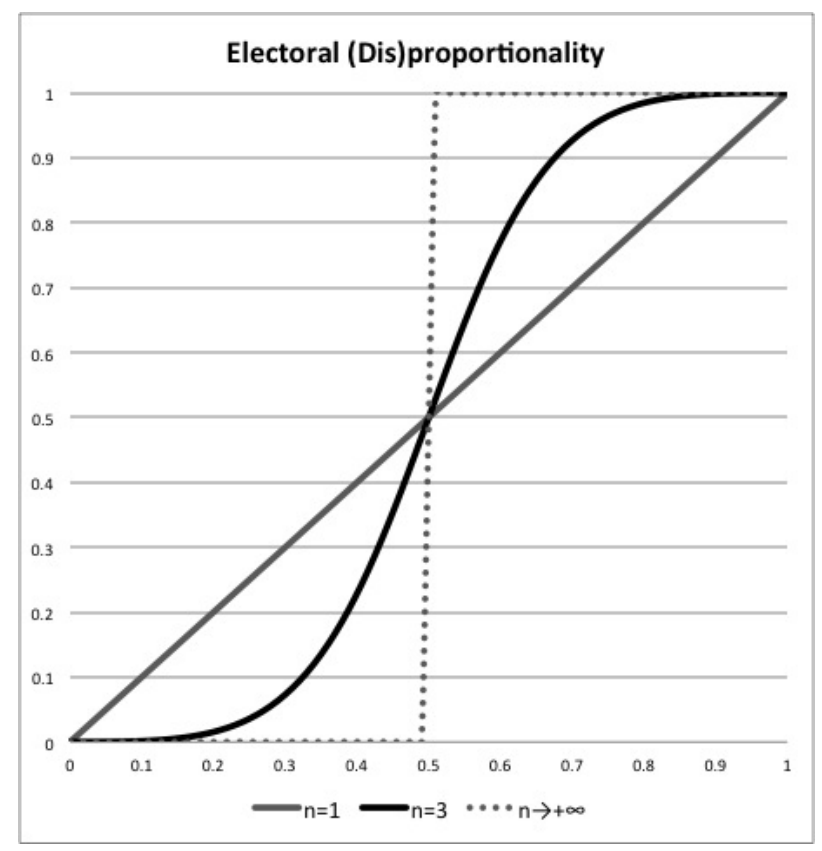

Figure 1: The weight of a party's proposal (i.e., its seat share) as a function of its vote share for the cases where $n=1, n=3$, and $n \rightarrow \infty$.

In existing models of pure proportional representation (e.g., Llavador 2006; Merrill and Adams 2007; Ortuño-Ortín 1997), the associated weights on parties' platforms are assumed to be proportional to parties' vote shares (i.e., $n=1$ ). As depicted in Figure 1 , by allowing $n$ to take values larger than one, we increase the weight put on the policy proposed by the winner of the election, for a given electoral outcome. This is true since assuming that $n \geqslant 1$ the weight function is convex for values smaller than one-half and concave for values larger than one-half. If $n \rightarrow \infty$, then parties actually compete in a winner-takes-all election where the implemented policy converges to the winner's proposed platform.

Notice that the weights determined through this specific functional form are identical to the seminal contest success function introduced by Tullock (1980, pp. 97-112). Recently, the application of this type of contest success function to the analysis of electoral systems has gained popularity. The work by Saporiti (2014) also analyzes electoral competition but in contrast to ours, only considers the two-party scenario and does not provide a general result for the two-party equilibrium. Herrera, Morelli, and Nunnari 
(2014) and Herrera, Morelli, and Palfrey (2014) focus on an another important aspect of democracies, namely turnout under alternative electoral rules.

As in most spatial models of this type, individuals vote for one of the parties once they observe the announced platforms. As a result, parties strategically announce their platforms, thereby determining voters' behavior, the outcome of the game, and the corresponding payoffs. With parties being the actual players of the game the equilibrium concept we apply is Nash equilibrium in pure strategies.

\section{Uniformly distributed voters}

For clarity of presentation, we first analyze the case of uniformly distributed voters. Before providing the equilibrium characterization, let us illustrate through an appropriate example how a disproportional electoral rule may provide centripetal forces.

Consider first the pure PR system (where $n=1$ ) depicted in Figure 2a. Let parties propose platforms at the extremes of the policy space $\left(p_{L}=0\right.$ and $\left.p_{R}=1\right)$ and assume that the ideal policy of the leftist party is $\pi_{L}=0.3$. The voter who is located at one-half is indifferent between the two proposed platforms $(\bar{\pi}=0.5)$. Voters to the left of the indifferent voter support the platform of the leftist party, while voters to the right of the indifferent voter support the rightist party. Given that voters are uniformly distributed, each party obtains $50 \%$ of the votes. Combining this vote share with the proportional system $(n=1)$, each party's platform has an equal $(50 \%)$ weight on the implemented policy. Hence, the implemented policy is one-half (which coincides with both the median and the ideal policy of the indifferent voter).

Let us explore the consequences of a deviation of the leftist party to a more moderate platform in such a proportional system (Figure 2b); let, for example, party L deviate from $p_{L}=0$ to $p_{L}=0.2$. Now, the indifferent voter moves further to the $\operatorname{right}(\bar{\pi}=0.6)$. Hence, party $L$ obtains $60 \%$ of the votes, while party $R$ obtains $40 \%$ of the votes. Party $L$ has a larger weight than before for the determination of the implemented policy (now $60 \%$ 


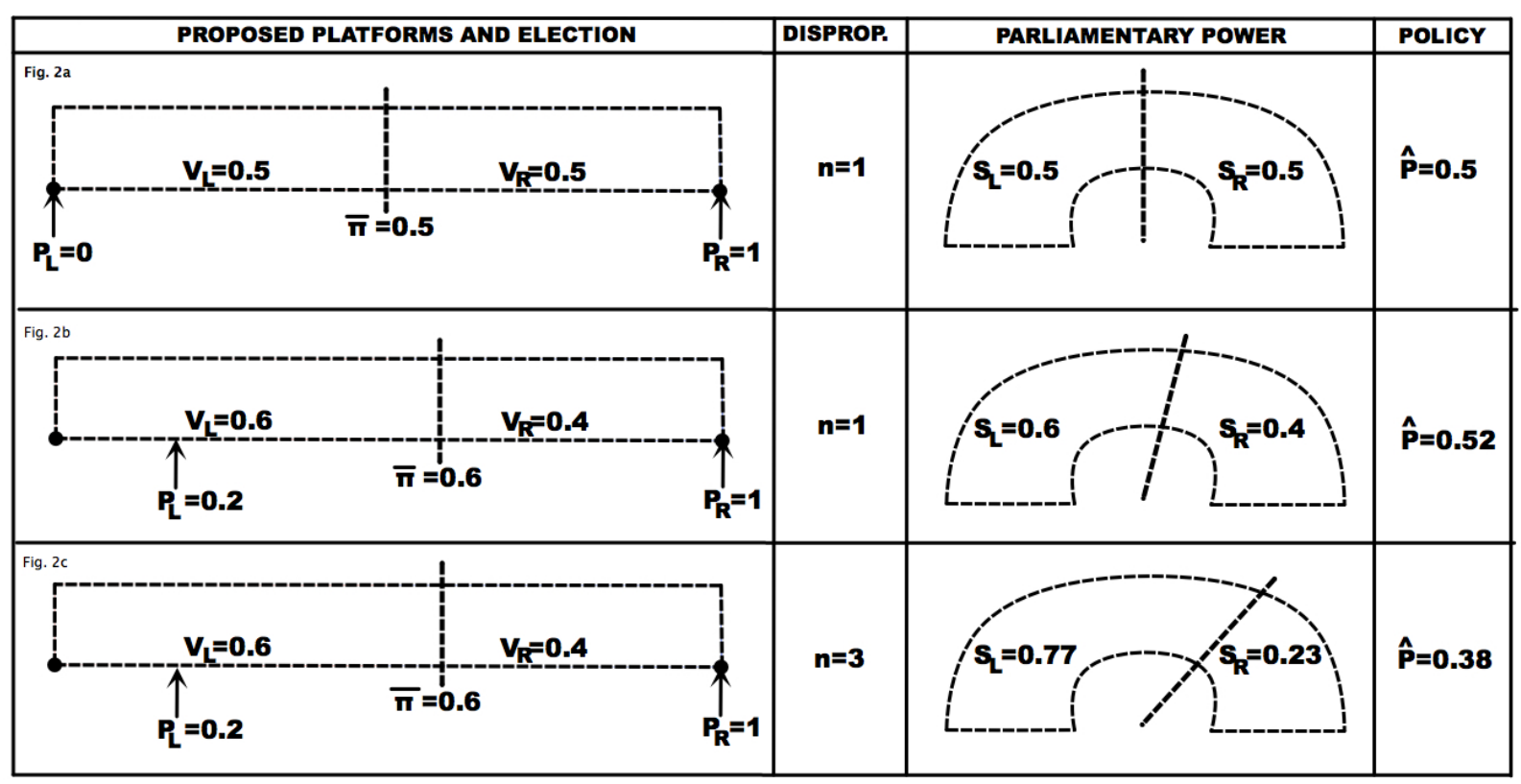

Figure 2: Centripetal incentives.

compared to $50 \%)$, but at the same time proposes a more moderate platform $\left(p_{L}=0.2\right.$ compared to $\left.p_{L}=0\right)$. Therefore, the implemented policy is $\hat{p}=0.52$. Since the ideal policy of party $L$ is to the left of the ideal policy of the median voter, party $L$ has no incentive to deviate from its initial strategy: By doing so, the implemented policy moves farther away from its ideal policy.

Consider now a more disproportional electoral system (let, for example, $n=3$ ), as depicted in Figure 2c. As before, if party $L$ announces platform 0.2 rather than zero, it obtains $60 \%$ of the vote share. Because of the disproportionality, this vote share translates to a disproportionally high weight of $77 \%$ on its proposed platform. In contrast to the case when $n=1$, this weight now compensates the loss from proposing a moderate platform. In this case, the implemented policy is 0.38 . Hence, party $L$ has an incentive to deviate from its initial strategy: By doing so, the implemented policy comes closer to its ideal policy.

The general mechanism providing centripetal forces as the degree of disproportionality of the electoral rule increases is clear. The following proposition enhances our understanding of the quantitative relationship between platform polarization and electoral 
rule disproportionality beyond simply its direction.

Proposition 1. Let $\pi_{i} \sim U[0,1]$. Then, (i) There exists a unique equilibrium $\left(p_{L}^{* *}, p_{R}^{* *}\right)=$ $\left(\frac{1}{2}-\frac{1}{2 n}, \frac{1}{2}+\frac{1}{2 n}\right)$, (ii) the distance between $p_{R}^{* *}$ and $p_{L}^{* *}$ is decreasing in $n$, and (iii) $\hat{p}=$ $\bar{\pi}=0.5$.

The unique Nash equilibrium in pure strategies of two-party elections $\left(p_{L}^{* *}, p_{R}^{* *}\right)$ for different values of electoral disproportionality $n \in[1,20]$ is depicted in Figure 3. If $n=1$ (i.e., no distortions are present), parties propose platforms at the extremes of the policy space $\left(p_{L}^{* *}=0\right.$ and $\left.p_{R}^{* *}=1\right)$. It is easy to calculate that the unique equilibrium when $n=3$ is $\left(p_{L}^{* *}, p_{R}^{* *}\right)=(1 / 3,2 / 3)$. In the extreme case of a winner-takes-all election $(n \rightarrow \infty)$, where the winning party can implement its platform, parties asymptotically converge to the median. Notice that the equilibrium characterization does not depend on parties' ideal positions but solely on the disproportionality of the electoral rule.

\section{The General Result}

While our results so far provided a clear intuition of our model's dynamics and how polarization in equilibrium is affected by different levels of disproportionality, we are now generalizing this result for a large family of voters' distributions. Notice that here we allow the society to be more inclined towards the left or the right of the policy space since we do not require the distribution to be symmetric. For purely technical reasons, we assume that $\pi_{L}=0$ and $\pi_{R}=1$. This extra assumption gives our game a strictly competitive nature that allows us to consider a very broad family of distributions of voters' ideal policies. Furthermore, as we argue after the statement of the proposition, the assumption of extreme parties may trivially be relaxed in the vast majority of admissible cases.

Proposition 2. Let $F$ be such that $F(x)^{n} /\left[F(x)^{n}+(1-F(x))^{n}\right]$ is a log-concave function. Then, (i) there exists a unique equilibrium $\left(p_{L}^{*}(n), p_{R}^{*}(n)\right)$ where $p_{L}^{*}(n)<p_{R}^{*}(n)$, (ii) if, given some $n_{0}$, we have that $0<p_{L}^{*}\left(n_{0}\right)<p_{R}^{*}\left(n_{0}\right)<1$, then $\hat{p}\left(n_{0}\right)=\bar{\pi}\left(n_{0}\right)=m$, 
$p_{R}^{*}\left(n_{0}\right)-p_{L}^{*}\left(n_{0}\right)=1 /\left[n_{0} f(m)\right]$, and for every $n_{1}$ and $n_{2}$ such that $n_{0}<n_{1}<n_{2}$, we have $\left|p_{L}^{*}\left(n_{1}\right)-p_{R}^{*}\left(n_{1}\right)\right|>\left|p_{L}^{*}\left(n_{2}\right)-p_{R}^{*}\left(n_{2}\right)\right|$, (iii) $p_{L}^{*}(n) \rightarrow p_{R}^{*}(n)$ when $n \rightarrow \infty$, and (iv) if $m=0.5$, then $p_{L}^{*}(n)=1-p_{R}^{*}(n)$ for every $n \geq 1$.

For any degree of disproportionality, there exists a unique Nash equilibrium in pure strategies. The leftist party proposes a policy to the left of the median voter, and the rightist party proposes a policy to the right of the median voter. In an interior equilibrium (i.e., $0<p_{L}^{*}(n)<p_{R}^{*}(n)<1$ ), the implemented policy coincides with the median voter's ideal point, while both parties propose platforms that diverge from the median by the same distance. Most relevant to our purposes, as the disproportionality of the electoral system increases, parties have incentives to propose more moderate platforms. Asymptotic convergence to the median is predicted in the case of winner-takes-all elections $(n \rightarrow \infty)$. The intuition behind parties' incentives to moderate their platforms is similar to the case of uniformly distributed voters.

Despite our analysis possibly allowing an asymmetric distribution of voters' ideal points, parties propose platforms that are symmetric with respect to the median. That is, even when the distribution is skewed towards the left or towards the right, parties may locate symmetrically around the median. The asymmetry in terms of the distribution is reflected in parties' payoffs; the closer the ideal policy of a party to the median voter's ideal policy, the larger the party's payoffs.

Another case of asymmetry that our model can accommodate is when parties are non-extreme (i.e., $0<\pi_{L}<m<\pi_{R}<1$ ). Consider first two extreme parties (i.e., $\pi_{L}=0$ and $\pi_{R}=1$ ) and some $F$ and $n$ such that the unique equilibrium is interior (i.e. $\left.0<p_{L}^{*}(n)<p_{R}^{*}(n)<1\right)$. The above proposition dictates that in such an equilibrium the implemented policy coincides with the ideal policy of the median voter. That is, when party $L$ chooses $p_{L}^{*}(n)$, the implemented policy is guaranteed never to be to the right of the ideal policy of the median voter for any $p_{R} \in[0,1]$. Otherwise, $p_{R}^{*}(n)$ would not be $R$ 's best response to $L$ choosing $p_{L}^{*}(n)$. This suggests that when party $L$ chooses $p_{L}^{*}(n)$, the unique best response of party $R$ is $p_{R}^{*}(n)$ even if $R$ was non-extreme (i.e. for 
any $\left.\pi_{R} \in(m, 1]\right)$. Similarly, when party $R$ chooses $p_{R}^{*}(n)$, the unique best response of party $L$ is $p_{L}^{*}(n)$ even if $L$ is non-extreme (i.e., for any $\left.\pi_{L} \in[0, m)\right)$. Hence, the interior equilibrium platforms $p_{L}^{*}(n)$ and $p_{R}^{*}(n)$ are independent of the exact locations of parties' ideal policies.

So, why do we make the assumption of parties' extreme preferences in the first place? This assumption makes our game strictly competitive, and, hence it provides our results a broad appeal since it allows us to take into account the rare cases of non-interior equilibria. The empirically relevant implication of the above formal result (the negative relationship between electoral rule disproportionality and platform polarization), though, is straightforwardly independent of such concerns. Hence, it is robust to parties having non-extreme policy preferences. This reassuring observation, along with the fact that the log-concavity condition is satisfied by a large family of distributions, guarantee that our work provides a broad picture of two-party elections under different degrees of disproportionality. ${ }^{7}$

Notice that our general result fully backs up the recent empirical results of Curini and Hino (2012) regarding the effect of the number of independent voters on platform polarization. The equilibrium condition, $p_{R}^{*}\left(n_{0}\right)-p_{L}^{*}\left(n_{0}\right)=1 /\left[n_{0} f(m)\right]$, clearly shows that polarization $\left(p_{R}^{*}\left(n_{0}\right)-p_{L}^{*}\left(n_{0}\right)\right)$ is decreasing in the density of moderate voters, who can be considered a proxy of the share of independent voters in the electorate (Curini and Hino 2012; Green 2007; Lin, Enelow, and Dorussen 1999).

\section{The Three Parties Case}

We now consider a three-party electoral race (a leftist, a centrist, and a rightist party). It is straightforward that the complexity of the analysis increases several orders in magnitude when we increase the cardinality of the set of players from two to three (e.g., Adams and

${ }^{7}$ For example, the log-concavity condition is satisfied when voters' ideal policies are distributed according to any unimodal Beta distribution (that is, $\pi_{i} \sim \operatorname{Beta}(\alpha, \beta)$ with $\alpha \geq 1, \beta \geq 1)$ 
Merrill 2006). For example, the game is no longer strictly competitive as when only two parties compete. Therefore, the equilibrium characterization cannot follow from a standard combination of the popular properties that strictly competitive games have (see proof of Proposition 2). Hence, to guarantee tractability, we must make further assumptions. First, we assume that the ideal policy of the centrist party is at one-half (that is, $\left.\pi_{C}=0.5\right)$, and the leftist and the rightist parties are extreme $\left(\pi_{L}=0\right.$ and $\pi_{R}=1$ ). Second, we consider an equilibrium in this case to be a pure-strategy Nash equilibrium such that the distribution of policy proposals is symmetric around the center of the policy space. Since three parties now compete in the election, each party's seat share is given by the following expression (Theil 1969; Taagepera 1986):

$$
S_{J}=\frac{V_{J}^{n}}{V_{L}^{n}+V_{C}^{n}+V_{R}^{n}}
$$

Therefore, the implemented policy function for the three-party model is accordingly defined as:

$$
\begin{aligned}
\hat{p}\left(p_{L}, p_{C}, p_{R}, n\right) & =\frac{V_{L}\left(p_{L}, p_{C}, p_{R}\right)^{n}}{V_{L}\left(p_{L}, p_{C}, p_{R}\right)^{n}+V_{C}\left(p_{L}, p_{C}, p_{R}\right)^{n}+V_{R}\left(p_{L}, p_{C}, p_{R}\right)^{n}} \times p_{L} \\
& +\frac{V_{C}\left(p_{L}, p_{C}, p_{R}\right)^{n}}{V_{L}\left(p_{L}, p_{C}, p_{R}\right)^{n}+V_{C}\left(p_{L}, p_{C}, p_{R}\right)^{n}+V_{R}\left(p_{L}, p_{C}, p_{R}\right)^{n}} \times p_{C} \\
& +\frac{V_{R}\left(p_{L}, p_{C}, p_{R}\right)^{n}}{V_{L}\left(p_{L}, p_{C}, p_{R}\right)^{n}+V_{C}\left(p_{L}, p_{C}, p_{R}\right)^{n}+V_{R}\left(p_{L}, p_{R}\right)^{n}} \times p_{R}
\end{aligned}
$$

The following result holds: ${ }^{8}$

Proposition 3. Let $\pi_{i} \sim U[0,1]$. Then, (i) there exists a unique equilibrium $\left(p_{L}^{* * *}, p_{C}^{* * *}, p_{R}^{* * *}\right)=$ $\left(\frac{1}{2}-\frac{1}{n+1}, \frac{1}{2}, \frac{1}{2}+\frac{1}{n+1}\right)$ and (ii) the distance between $p_{R}^{* * *}$ and $p_{L}^{* * *}$ is decreasing in $n$ (iii) $\hat{p}=\bar{\pi}=0.5$.

${ }^{8}$ Without providing a formal definition of voters' strategies, it is necessary to mention that each voter $i$ supports the party $j$ that proposes the closest platform to his ideal policy. If a voter is indifferent between two or even three platforms, then he votes for any of his top-ranked parties with equal probability. 
The centrist party proposes a platform equal to its ideal policy $\left(p_{C}^{* * *}=\pi_{C}=0.5\right)$. The two other parties differentiate and propose more extreme platforms. The extent to which parties differentiate depends on the level of disproportionality (see Figure 3, which depicts the proposed platforms $\left(p_{L}^{* * *}, p_{R}^{* * *}\right)$ for different values of electoral disproportionality $n \in$ $[1,20])$. The more proportional the electoral system is, the higher are the centrifugal forces, and hence, polarization increases. Clearly, if parties compete in a winner-takes-all election $(n \rightarrow \infty)$, the platforms of the two peripheral parties asymptotically converge to the median (that is, $\left.\left(p_{L}^{* * *}, p_{C}^{* * *}, p_{R}^{* * *}\right) \rightarrow(0.5,0.5,0.5)\right){ }^{9}$

Notice that in all results presented above, including the one allowing for an asymmetric distribution of voters, the implemented policy coincides with that of the median voter. This implies that the citizens' welfare is independent of the precise value of $n$. Here, we would like to stress that this invariance of social welfare to electoral changes is only apparent and a consequence of our choice to interpret our model as a parliamentary-mean model where the implemented policy is a convex combination of the proposed platforms. If, alternatively, one chooses to interpret our model as a dominant-party model (Faravelli and Sanchez-Pages 2014; Iaryczower and Mattozzi 2013; Merrill and Adams 2007) - by interpreting parties' seat shares as the probabilities that each party can implement its proposed platform - then, conditional on parties being risk neutral, the equilibrium results presented in Propositions 2 and 3 remain unaffected. Now it becomes clear that even if the expected policy outcome is still invariant in $n$, the variance of the policy outcome is decreasing in $n$ (both in two- and three-party elections), and hence, social welfare is increasing in $n$. As a result, a welfare analysis of this interpretation of our model shows that if voters are risk-averse and care both about the implemented policy (in expectation) and its variance, they are better off under disproportional electoral systems.

\footnotetext{
${ }^{9}$ The qualitative implications of the above proposition directly extend to other distributions and are not restricted to the uniform case.
} 


\section{Measures of Polarization}

Having characterized the equilibrium under different theoretical specifications and having made clear the interaction of the centripetal and the centrifugal forces of the political environment, we now turn attention to the concept of polarization. We will not argue for or against any definition of polarization. We merely utilize our theoretical findings in order to illustrate the importance of the choice of a given polarization measure in empirical studies.

The empirical literature (Table A1) has mainly considered two measures of polarization. The first is one that we have used so far in our theoretical analysis, where polarization is defined as the distance between the two MDP. The second measure of polarization is the DI, formally defined as follows:

$$
D I=\sqrt{\sum_{j} V_{j}\left(\frac{p_{j}-\bar{p}}{0.5}\right)^{2}}
$$

where $\bar{p}$ denotes the weighted mean of parties' proposed platforms (each party $j$ is weighted by its vote share $\left.V_{j}\right), p_{j}$ is the platform proposed by party $j$, and the difference between the two is normalized by the mid-point ideology position, which in our model is 0.5 . The index takes value zero when all parties converge to a single position and one when parties are equally split between the two most extreme positions.

Figure 3 summarizes our theoretical findings. On the left we plot the results presented in Propositions 1 and 3 and as one can see the following relationship holds:

Remark 1. Polarization (measured by the MDP) in a three-party election is larger than in a two-party election $\left(p_{R}^{* * *}-p_{L}^{* * *} \geq p_{R}^{* *}-p_{L}^{* *}\right.$ with the equality holding for $\left.n=1\right)$.

First, notice that polarization (measured by the MDP) is clearly decreasing in the level of disproportionality both in two- and three-party elections. Second, the centrifugal force identified in the proportionality of the electoral system is amplified as the number of competing parties increases from two to three. The presence of a third party makes 


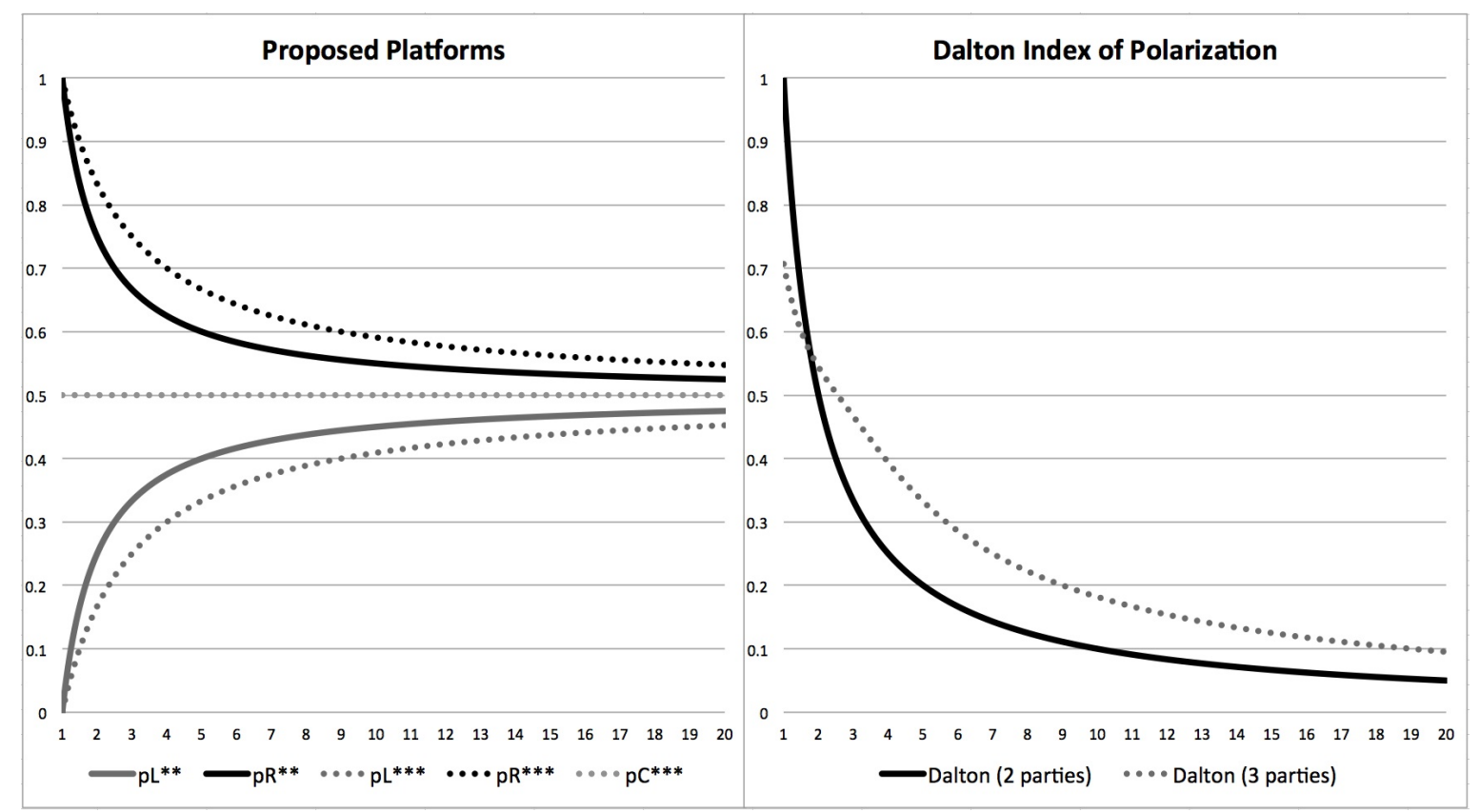

Figure 3: Left: The effect of electoral disproportionality $n \in[1,20]$ on proposed platforms for two- $\left(p_{L}^{* *}, p_{R}^{* *}\right)$ and three-party competition $\left(p_{L}^{* * *}, p_{R}^{* * *}, p_{C}^{* * *}\right)$, as characterized in Propositions 1 and 3. Right: Polarization measured by the DI in the case of two- and three-party elections for $n \in[1,20]$.

competition for centrist voters tougher, and hence, parties have fewer incentives to moderate their policies in return for a slightly larger share of moderate votes. Moreover, when there is no third party, as the left-wing party (for instance) diverges from the center of the voter distribution, it loses votes (and seats) to its right-wing rival, thereby pulling the parliamentary mean sharply to the right. By contrast, when a centrist third party is present, policy divergence by the left-wing party causes it to lose votes (and seats) to the centrist party, not the right-wing party as in the two-party case. In this instance, transferring seats to the centrist party does not pull the parliamentary mean as sharply to the right as does transferring seats to the right-wing party. So, in line with the results by Adams and Merrill (2006), the presence of the centrist party partially "insulates" the peripheral parties from the policy consequences of losing votes due to taking more extreme positions. ${ }^{10}$

From a comparative perspective, the distance between the MDP in the unique equi${ }^{10} \mathrm{We}$ are grateful to a referee for recommending the above interpretation. 
librium of the three-party election is larger than in the two-party election (for any $n>1$, it holds that $p_{L}^{* * *}<p_{L}^{* *}$ and that $\left.p_{R}^{* * *}>p_{R}^{* *}\right)$. As far as the DI is concerned, notice first that similar to the MDP, the DI is also decreasing in the level of disproportionality both in two- and three-party elections. Nevertheless, given that the DI is affected by parties' vote shares, the relationship between polarization (measured by the DI) and the number of parties for a given level of disproportionality is no longer straightforward (see Figure $3)$.

Remark 2. Polarization (measured by the DI) in a three-party election is larger (smaller) than in a two-party election when $n$ is large (small).

When $n$ is small, the DI for the two-party election takes high values, given that each party proposes an extreme policy platform and that each obtains half of the votes. For the same small values of $n$, the DI in the three-party election is smaller than the DI of the two-party election because of the presence of the centrist party. Given the low levels of disproportionality (i.e., small $n$ ), the centrist party actually obtains a large vote share that drives the DI of the three-party election to low levels. As $n$ increases, though, the leftist and rightist parties' platforms become more moderate. This makes the vote share of the centrist party - and thus, the influence of the centrist party on the level of polarization (measured by the DI) - decrease and essentially disappear (when $n$ takes very large values). Hence, when $n$ is large, the DI should eventually converge to the MDP. From this second remark, the effect of the number of parties on the DI is conditional on the level of disproportionality. Nevertheless, this result is proven only for the comparison of two- and three-party models. The effect of the number of parties on the DI is inconclusive when we extend our model to include more than three parties. As a result, no testable predictions can be stated. 


\section{Empirical Analysis}

In line with our theoretical analysis, we state the following two hypotheses regarding the determinants of platform polarization.

(H1) Electoral System Hypothesis (Propositions 1 and 2): Platform polarization (measured either by the DI or the MDP index) is decreasing in the disproportionality of the electoral rule $n .{ }^{11}$

(H2) Number of Parties Hypothesis (Remark 1): Platform polarization (measured by the MDP index) is increasing in the number of competing parties.

Both hypotheses have been explored by a number of related studies yielding inconclusive empirical findings (see Table A1 in the online appendix). While several approaches fail to garner enough support for H1 (e.g., Budge and McDonald 2006; Dalton 2008; Ezrow 2008), others provide (conditional) evidence in favor of either H1 (e.g., Calvo and Hellwig 2011; Dow 2011) or H2 (Andrews and Money 2009). Curini and Hino (2012) find support for two additional institutional hypotheses - the cabinet-parties conditional hypothesis and the electoral spill-over hypothesis - while Calvo and Hellwig (2011) find conditional support for $\mathrm{H} 1$ for the large governing parties. ${ }^{12}$

\footnotetext{
${ }^{11}$ Notice that the theoretical model points at a non-linear relationship between the electoral rule disproportionality and platform polarization. While in the empirical analysis we follow the literature by employing linear regression models, the non-linearity of the disproportionality on polarization is captured in the robustness checks when the independent variable capturing the disproportionality of the electoral rule is the log average district magnitude. Our results are also robust to the inclusion of $\log n$ rather than $n$ as an independent variable.

${ }^{12} \mathrm{We}$ also include the variables introduced by Curini and Hino (2012) as additional controls in our regressions, but we do not find significant support for the electoral spillover hypothesis. Some specifications provide partial support regarding the cabinet-parties conditional hypothesis. Nevertheless, Curini and Hino (2012) also test a simpler version of their model that includes only $\mathrm{H} 1$ and $\mathrm{H} 2$ and is therefore directly comparable to our
} 
Our empirical analysis shows that the main reason why several existing studies find weak (or even no) support for the electoral-system hypothesis is that most of them utilize small and unbalanced data sets over a short time frame (see Table A1). As a result, most of these studies lack enough observations of electoral rule transitions per country to estimate the within-country effect of disproportionality on polarization. On top of it, by including very few observations for each country - in many instances only one - even the cross-country effects, that several of those papers are in fact estimating, are based on a single observation per country. That is, they take into account only a snapshot of cross-country polarization levels, making it impossible to disentangle the variation in polarization that is related to electoral rules from country-specific trends or other intrinsic characteristics (e.g., time or country-specific shocks that might have occurred during this limited period of observation). Therefore, by considering a large and balanced panel, with an average of 13 observations for each country, our work is an improvement on both fronts: Not only do we introduce some within-country variation in the electoral rule disproportionality, but we also improve significantly the cross-country comparison, thus obtaining a more accurate picture of the effects of interest.

model presented in columns 1 through 3 in Table 1 . The fact that we find a statistically significant effect of disproportionality on polarization (when we estimate their model using our data) while they do not is, therefore, clear evidence that our different predictions cannot be attributed to these two additional hypotheses.

Calvo and Hellwig (2011) follow a different empirical approach and predict that the disproportionality of the electoral rule acts as a centripetal force only for dominant parties, while it is a centrifugal force for smaller ones that are predicted to occupy more extreme positions. We, on the other hand, predict unconditional support for H1, irrespective of party size. 


\section{Data Description and Measurement}

We combine three different sources to construct a balanced panel that combines electoral, political, institutional, socioeconomic, and demographic data for more than 300 elections from 23 OECD countries during the period from 1960 to 2006 (Armingeon, Potolidis, Gerber, and Leimgruber 2010; Carey and Hix 2011; Volkens, Lacewell, Lehmann, Regel, Schultze, and Werner 2012). ${ }^{13}$ We describe our data and main variables in this section and provide the summary statistics in Table A2 of the online appendix.

The Dependent Variable: Our dependent variable, platform polarization, is constructed using data from the Volkens, Lacewell, Lehmann, Regel, Schultze, and Werner (2012) Comparative Manifesto Project (CMP) dataset compiled by the Berlin Centre for Social Research (WZB). The latter records the positions of the platforms proposed by hundreds of political parties, dating back to 1946, in a unidimensional ideology (left-right) space. $^{14}$

${ }^{13}$ The 23 countries included in our sample are Australia, Austria, Belgium, Canada, Denmark, Finland, France, Germany, Greece, Iceland, Ireland, Italy, Japan, Luxembourg, Netherlands, New Zealand, Norway, Portugal, Spain, Sweden, Switzerland, the UK, and the USA. In the specifications where we use the data of Carey and Hix (2011) our sample consists of 21 countries (data on Iceland and Luxembourg are missing).

${ }^{14}$ Obviously, the CMP does not provide data for all parties competing in the election. The parties in our sample represent on average $96 \%$ of votes cast, with no important differences across electoral systems. The CMP also records parties not obtaining representation in parliament. The vote shares of the latter range from the very low $0.77 \%$ of the Social Credit Party in Canada (1968), 0.56\% and 0.76\% (in 2002 and 2008) of the Communist Party of Austria, 1.5\% of the leftist Democratic Labor Party of Australia in 1974, 1975 and 1977, 2-3\% of the UK Independence Party to the more than 5\% of the Australian Democrats and the Social Credit party in New Zealand to the staggering $12 \%$ of the Front Nationale (FN) in the 2002 French election. This information on the political platforms of various small parties, even in countries with majoritarian electoral 
In order to maintain consistency with our theoretical model, as well as with existing literature, we measure polarization in two different ways. First, we consider polarization to be the distance between the two MDP (e.g., Andrews and Money 2009; Budge and McDonald 2006). Second, following Dalton (2008), we formally define the DI of platform polarization for country $i$, in election year $t$ exactly as previously presented, substituting the platform proposed by party $j, p_{j}$, with the ideological (platform) position of that party in election year $t$ at country $i$, weighted by the party's vote share. Both measures of polarization are standardized and take values from zero to ten. ${ }^{15}$ We present our estimates using both measures and show that our main results are consistent with the findings of our theory and the two hypotheses outlined above.

The Main Explanatory Variables: Our key explanatory variable is the measure of the electoral rule disproportionality (parameter $n$ ) as defined in our theoretical section. By combining data from two different sources (Armingeon, Potolidis, Gerber, and Leimgruber 2010; Carey and Hix 2011) we estimate the disproportionality parameter $n$ for 21 countries in our sample by applying the formula proposed by Taagepera (1986):

$$
n=[\log (V) / \log (S)]^{(1 / M)}
$$

where $V$ is the total number of voters, $S$ is the total number of parliamentary seats, and $M$ is the average electoral district magnitude. Estimating the disproportionality rules, implies that finding higher levels of polarization (at least as measured by the DI) in countries that apply more proportional rules cannot be an artifact of the data collection process.

${ }^{15}$ In our theoretical discussion the DI takes a value from zero to one since vote shares have been defined in this interval. In our empirical analysis, vote shares are given by percentages, and the DI simply takes values from zero to ten. Curini and Hino (2012) also use the DI, while Dow (2011) and Ezrow (2008) use a very close analogue that incorporates all parties' positions weighted by their vote shares. 
parameter $n$ allows for a tight fit between our model's predictions and our empirical estimation. An additional advantage of using this variable, given that the electoral rule is a sluggish institutional variable, is that it is continuous and exhibits some withincountry variation, therefore allowing for both within- and cross-country comparisons. Nevertheless, in order to insulate our results, we also repeat our estimates using two alternative measures of disproportionality, both of which provide qualitatively identical results. The first is a binary variable that takes the value of one whenever the FPTP rule with Single-Member Districts (SMD) is applied and zero otherwise. The second is the natural log of the average electoral district magnitude, representing the idea that a larger district magnitude reduces the effective threshold required for a party to occupy a parliamentary seat, and hence, making the electoral system more proportional (Taagepera 1986; Carey and Hix 2011).

The use of these three alternative measures not only increases the robustness of our findings but also allows us to address any concerns related to limited within-country variation and endogeneity. On one hand, the binary variable records only a radical change from PR to a FPTP rule and vice versa. Such radical changes occurred only in three countries (Greece, Italy and New Zealand). Since these changes are not frequent, it is less likely that our analysis suffers from an endogeneity problem, especially since our dependent variable varies relatively more than any of our independent ones. On the other hand, the two continuous versions of our independent variable can partially address the problem of limited within-country variation since both the disproportionality parameter $n$ and the district magnitude vary in more than half of the countries of our sample. Importantly, under all three specifications our results are robust, statistically significant, and identical in the direction of the effect.

Following the literature (e.g., Andrews and Money 2009; Curini and Hino 2012), we test the number of competing parties hypothesis (H2) using the Effective Number of Parties (ENP) index and its natural logarithm as our independent variables. ${ }^{16}$

\footnotetext{
${ }^{16}$ Laakso and Taagepera (1979) define the effective number of political parties as
} 


\section{Empirical Estimation}

Since empirical evidence (e.g., Gallagher 1991) and theoretical literature (e.g., Duverger 1954) suggest that electoral rules may also affect polarization through the structure of the party system (e.g., the number of parties), in Model 1 we test our first two hypotheses jointly in order to prevent a biased estimation (Curini and Hino 2012). This model serves as our benchmark since most of the literature tests these two hypotheses (e.g., Andrews and Money 2009; Curini and Hino 2012; Dalton 2008; Dow 2011; Ezrow 2008). According to $\mathrm{H} 1$, we expect $\beta_{1}<0$, as more disproportional rules should lead to less polarization. ${ }^{17}$ From H2, we expect $\beta_{2}>0$ when we measure polarization by the MDP index. Formally, we estimate Model 1.a as:

$$
\text { POLARIZATION } N_{i t}=\beta_{0}+\beta_{1} \times \text { DISPROPORTIONALITY } Y_{i t}+\beta_{2} \times E N P_{i t}+\epsilon_{i t}
$$

Model 1.b extends Model 1.a by including year dummies (denoted by $\lambda_{t}$ ), whereas in Model 2.a we also control for a set of additional institutional variables $\mathbf{X}_{i t}^{\prime}$-including but not limited to those introduced by Curini and Hino (2012) - such as a coalition habits dummy, the number of parties participating in government/cabinet and their interaction, the type of political regime (presidentialism vs. parliamentarianism), the degree of institutional constraints, the years of consolidated democracy, a dummy variable indicating government change, and the ideological distance between the current and previous government. In Model 2.b, we include country fixed effects (country dummies $\alpha_{i}$ ) in order to fully exploit the structure of our data and account for country-specific characteristics.

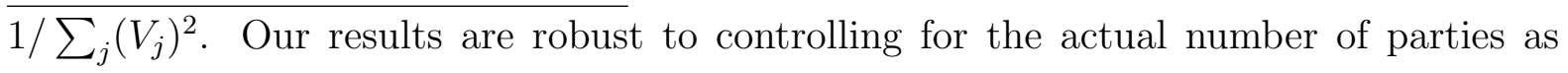
presented in the theoretical model (available upon request).

${ }^{17}$ When the $\log$ of average district magnitude is employed as our explanatory variable, we expect $\beta_{1}$ to be positive. 
Formally, Model 2.a is estimated as:

POLARIZATION $N_{i t}=\beta_{0}+\beta_{1} \times$ DISPROPORTIONALITY $Y_{i t}+\beta_{2} \times E N P_{i t}+\mathbf{X}_{i t}^{\prime} \times \gamma+\lambda_{t}+\epsilon_{i t}$

and Model 2.b as:

POLARIZATION $N_{i t}=\beta_{0}+\beta_{1} \times D I S P R O P O R T I O N A L I T Y_{i t}+\beta_{2} \times E N P_{i t}+\mathbf{X}_{i t}^{\prime} \times \gamma+\lambda_{t}+\alpha_{i}+\epsilon_{i t}$

We further estimate a random effects model (Model 2.c), given that our main covariate of interest (electoral rule) either does not vary at all or exhibits small variation within each country. In the first case, the unit-invariant independent variable (electoral rule dummy) will be perfectly collinear with the set of country dummy variables, thus making it impossible to estimate the unique effects of that variable (Clark and Linzer 2015). In the latter case, our continuous independent variables change gradually over time in most instances (particularly relative to changes in the dependent variable). However, if "the correlation between the sluggish covariate and the unit [country] fixed effects is high enough, this can greatly destabilize estimates of the effect of the independent variable" (Clark and Linzer 2015). That is, the sluggish or non-varying independent variable solves any possible endogeneity issues at the cost of rendering within-country estimates uninformative, thus permitting only cross-country comparisons. Fortunately, random effects are not subject to these limitations. We therefore present all of our subsequent estimates under both specifications.

We finally estimate two additional versions of the above model: using the log of ENP to test H2 (Model 3) and replacing the DI with the MDP (Model 4). Moreover, in the online appendix (Table A3), we estimate variants of Models 3 and 4 using the natural $\log$ of average electoral district magnitude as an alternative measure of the electoral rule disproportionality (as in Carey and Hix 2011) . 


\section{Results and Discussion}

The results of estimating our main econometric model are presented in Table 1. They provide strong support for our main hypothesis (H1) regardless of how the (dis)proportionality of the electoral rule is measured. In all specifications, more disproportionate electoral rules are associated with lower levels of polarization. This finding is robust to various alterations to the model, including different ways of measuring the independent variables (see Tables 2, A3, and A4), the inclusion of more control variables (Models 2 and 3), and random effects. Hence, our empirical analysis verifies the main theoretical prediction of the model on the effect of electoral rule (dis)proportionality on polarization.

[Insert Table 1 and Table 2 about here]

Our results call for a revision of the thesis that electoral institutions have no impact on polarization (e.g., Andrews and Money 2009; Budge and McDonald 2006; Curini and Hino 2012; Dalton 2008; Dow 2001; Ezrow 2008) and reinforce recent work by Dow (2011) and Calvo and Hellwig (2011) that finds some conditional support for the electoral system (H1) hypothesis. Notice that not only is the coefficient $\beta_{1}$ negative (as predicted) and statistically significant, but it is also large in magnitude. Our estimates associate a change from a PR to a FPTP rule (electoral rule becomes more majoritarian) with a two standard deviations decrease in polarization.

The number of parties hypothesis (H2) is confirmed at the conventional levels of significance (that is, $5 \%$ or lower) in Model 4 where polarization is measured by the MDP index. ${ }^{18}$ The effect of the number of parties on polarization is strong (especially when random effects are employed) and positive, as predicted. This finding is consistent with our theoretical prediction (Remark 1) and the fact that polarization, when measured by the MDP, is increasing in the number of competing parties. In all other specifications,

${ }^{18}$ The models where $\mathrm{H} 2$ is validated are presented in Table 2, where for consistency we control for the log of ENP following Andrews and Money (2009), and in Table A3 (Models 4.c and 4.d). 
when the DI is our dependent variable, ${ }^{19}$ while the point estimate of the coefficient $\beta_{2}$ is still positive, it is much smaller in magnitude and not statistically significant at any conventional level (5\% or lower).

Regarding the inclusion of country and year fixed effects in some econometric specifications, we note that their inclusion is not the reason that our results differ from previous findings. This can be seen in Table 1 where the estimates obtained with a fixed effects model (2.b) are qualitatively identical with those obtained from a model that omits country and year dummies (1.a, as for example in Curini and Hino 2012) and with those from a model that includes the additional institutional controls (2.a). Therefore, the differences with existing approaches should be attributed to our improved data set and estimation techniques.

Moreover, for the reasons previously explained, we also estimated a random effects (RE) model. Since the results we obtain using both estimators are qualitatively identical, equally statistically significant, and consistent we conclude that these concerns have been successfully addressed. In fact, the use of both fixed and random effects allows us to frame the true effect of electoral rule disproportionality by estimating upper (FE) and lower (RE) bounds.

In addition to estimating a RE model, in Table 3, we more closely examine those countries in our sample that underwent "radical" electoral rule changes. In particular, we consider Greece, New Zealand, and Italy. Since our FE estimates (when we use the FPTP dummy as the dependent variable) are mainly exploiting cross-country variation, it is instructive to examine separately those countries that are mainly responsible for any within-country variation. In total, Greece underwent two electoral rule reforms (one proportional and one majoritarian), New Zealand a proportional one (from FPTP with SMD to mixed-member PR), and Italy a majoritarian one (from pure PR to a mixed

\footnotetext{
${ }^{19} \mathrm{~A}$ notable exception is Model 3 .b when we estimate a random effects model while
} also using the natural log of ENP in order to test $\mathrm{H} 2$. 
system with a majority premium). ${ }^{20}$ In total, we have four electoral rule transitions, two proportional and two majoritarian. As shown in Table 3, in all four cases, changes in the direction of polarization are consistent with our theory. Proportional transitions induce an increase in mean polarization (for subsequent periods), while majoritarian ones induce a large decrease. Moreover, despite the small sample size, all changes in polarization are statistically significant at any conventional level and relatively large in magnitude. Thus, our case-study analysis is in line with our previous estimates.

[Insert Table 3 about here]

Overall, our empirical results yield robust support for the main prediction of the theoretical model on the effect of electoral rule (dis)proportionality on platform polarization. The combination of our theoretical and empirical findings points at the electoral rule disproportionality as a crucial institutional determinant of platform polarization.

\section{Concluding Remarks}

Our work has implications for the design of electoral institutions, as our analysis surfaces an interesting trade-off between the need for more democratic pluralism and wider

${ }^{20}$ The electoral rule introduced in Italy in 1993 distributed seventy five percent of the seats according to a FPTP system and twenty five percent of the seats according to a PR system. While all parties competed in the nationwide PR system, parties formed pre-electoral pacts when competing under the disproportional single member districts. That is, voters faced different choices in the nationwide district compared to the single member one and hence different polarization levels arise for the two systems. In the table, and in order to focus on the majoritarian transition, we compare the pre-1993 levels of polarization with the post-1993 ones in the FPTP system taking into account any pre-electoral pacts. Interestingly, the post-1993 polarization in the PR component of the rule (equal to 3.48) is larger than the FPTP one and not statistically different from the pre-1993 (also PR) levels. 
political representation (served by more proportional rules) and political stability and moderation (served by more majoritarian rules). Hence, the choice of one class of rules over the other is not straightforward and depends on individual party-system characteristics and the attributes of each polity.

Because this paper is a first attempt to introduce the electoral rule disproportionality as modeled by Theil (1969) in a Downsian setup, several relevant questions remain open. Assumptions regarding voters' behavior, other than the ones presented, should be carefully explored. A simple extension of the model suggests that our results are robust to allowing voters to abstain. If, for instance, one considers that the society is normally distributed around the median and that alienated voters whose ideal policies are "sufficiently" away from the parties' platforms abstain, then an increase in the disproportionality of the electoral rule would still reduce the level of polarization.

Another important aspect of our model is that voters are expressive and support the party that proposes the platform closest to their ideal point. But what if some voters behave instrumentally? Intuition suggests that the presence of instrumental voters provides further centrifugal incentives to political parties (Llavador 2006; De Sinopoli and Iannantuoni 2007). As before, a simple extension of the model shows that our main result would persist. That is, the degree of polarization would be higher when compared to the case of an expressive electorate but the direction of the effect of the degree of electoral rule disproportionality on the level of platform polarization would not be affected. But what if, as widely accepted, the electoral system itself endogenously determines the share of voters that behave instrumentally?

Ultimately, the extension of our multi-party model to more general setups is desirable. Our results for the three-party case assume that the centrist party has an ideology midway between the two extreme parties. Despite technical complexities we can claim that the main intuitions and results regarding polarization under different levels of electoral rule disproportionality are still valid when parties are centrist "enough" and disproportionality 
exists to a reasonable degree. ${ }^{21}$ Nevertheless, and given the importance of Duverger's work, further exploration of the proposed model on the interplay of electoral systems and the number of competing parties may provide interesting insights.

${ }^{21}$ The interested reader could refer to the online appendix where we present these results in more detail. 
TABLE 1: ELECTORAL RULE DISPROPORTIONALITY AND PLATFORM POLARIZATION IN OECD (1960-2007): RANDOM AND FIXED EFFECTS REGRESSIONS

\begin{tabular}{|c|c|c|c|c|c|c|c|c|c|c|}
\hline & \multirow{3}{*}{ Explanatory Variables } & \multicolumn{9}{|c|}{ Dalton Index (DI) of Platform Polarization } \\
\hline & & \multirow{2}{*}{$\begin{array}{c}\text { Model 1.a } \\
\text { (1) }\end{array}$} & \multicolumn{2}{|c|}{ Model $1 . b$} & \multicolumn{2}{|c|}{ Model 2.a } & \multicolumn{2}{|c|}{$\begin{array}{c}\text { Model } 2 . b \\
\text { Fixed Effects }\end{array}$} & \multicolumn{2}{|c|}{$\begin{array}{c}\text { Model 2.c } \\
\text { Random Effects }\end{array}$} \\
\hline & & & (2) & (3) & (4) & (5) & (6) & (7) & (8) & (9) \\
\hline H1 & Electoral Rule Dummy $($ FPTP $=1)$ & $\begin{array}{l}-0.377 \\
(0.148)\end{array}$ & $\begin{array}{l}-0.471 \\
(0.168)\end{array}$ &.-- & $\begin{array}{l}-0.561 \\
(0.196)\end{array}$ & $-\because-$ & $\begin{array}{r}-1.326 \\
(0.268)\end{array}$ &.-- & $\begin{array}{c}-0.565 \\
(0.194)\end{array}$ & $-\because-$ \\
\hline H1 & Electoral Rule Disproportionality $(n)$ & -.- &.-- & $\begin{array}{r}-0.156 \\
(0.089)\end{array}$ &.-- & $\begin{array}{r}-0.208 \\
(0.090)\end{array}$ &.-- & $\begin{array}{l}-0.398 \\
(0.156)\end{array}$ & $-\because-$ & $\begin{array}{r}-0.200 \\
(0.091)\end{array}$ \\
\hline H2 & Effective Number of Parties (ENP) & $\begin{array}{r}0.020 \\
(0.069)\end{array}$ & $\begin{array}{r}0.028 \\
(0.073)\end{array}$ & $\begin{array}{r}0.046 \\
(0.078)\end{array}$ & $\begin{array}{r}0.142 \\
(0.076)\end{array}$ & $\begin{array}{r}0.160 \\
(0.092)\end{array}$ & $\begin{array}{r}-0.012 \\
(0.151)\end{array}$ & $\begin{array}{r}0.004 \\
(0.154)\end{array}$ & $\begin{array}{r}0.147 \\
(0.076)\end{array}$ & $\begin{array}{r}0.176 \\
(0.093)\end{array}$ \\
\hline & Random effects & $x$ & $x$ & $x$ & $x$ & $x$ & $x$ & $x$ & $\checkmark$ & $\checkmark$ \\
\hline & Country fixed effects & $x$ & $x$ & $x$ & $x$ & $x$ & $\checkmark$ & $\checkmark$ & $x$ & $x$ \\
\hline & Year dummies & $x$ & $\checkmark$ & $\checkmark$ & $\checkmark$ & $\checkmark$ & $\checkmark$ & $\checkmark$ & $\checkmark$ & $\checkmark$ \\
\hline & Other institutional controls & No & No & No & Yes & Yes & Yes & Yes & Yes & Yes \\
\hline & $R^{\wedge} 2$ & $\begin{array}{l}0.039 \\
307\end{array}$ & $\begin{array}{c}0.176 \\
307\end{array}$ & $\begin{array}{c}0.176 \\
255\end{array}$ & $\begin{array}{c}0.308 \\
237\end{array}$ & $\begin{array}{c}0.299 \\
237\end{array}$ & 0.423 & 0.413 & $\begin{array}{l}0.307 \\
237\end{array}$ & 0.295 \\
\hline
\end{tabular}

Robust standard errors clustered at the country level reported in parentheses. Columns 1 to 3 (Models $1 . a$ and $1 . b$ ) replicate the estimates of the econometric specification by Curini and Hino (2012) on our data set (with the inclusion of year dummies in all specifications from column 2 and onwards). In columns 4 and 5 (Model 2.a) we estimate the augmented model of Curini and Hino (2012) including their additional institutional hypotheses (coalition habits and multiple office elections). In columns 6 and 7 (Model 2.b) we estimate a fixed effects model. In columns 8 and 9 (Model 2.c) we estimate a random effects model. Other institutional controls include: a (dummy) variable indicating strong coalition habits and its interaction with ENP, the number of parties participating in government, the type of political regime (presidentialism or parliamentarianism), the degree of institutional constraints (a categorical variable taking values from $0-6$ ), years of consolidated democracy, a (dummy) variable indicating government change and the ideological distance between current and previous government. Columns 4 to 9 have fewer observations due to missing data for some institutional variables for the period from 1960 to 1980 . Column 3 has fewer observations as we cannot estimate parameter $n$ for Iceland and Luxembourg due to missing data. 
TABLE 2: ELECTORAL RULE DISPROPORTIONALITY AND PLATFORM POLARIZATION IN OECD (1960-2007): DALTON INDEX AND MOST DISTANT PLATFORMS

\begin{tabular}{|c|c|c|c|c|c|c|c|c|c|}
\hline & \multirow{4}{*}{ Explanatory Variables } & \multicolumn{4}{|c|}{ Dalton Index (DI) of party-system polarization } & \multicolumn{4}{|c|}{ Most Distant Platforms (MDP) Index } \\
\hline & & \multirow{2}{*}{\multicolumn{2}{|c|}{$\begin{array}{c}\text { Model 3.a } \\
\text { Fixed Effects }\end{array}$}} & \multirow{2}{*}{\multicolumn{2}{|c|}{$\begin{array}{c}\text { Model } 3 . b \\
\text { Random Effects }\end{array}$}} & \multirow{2}{*}{\multicolumn{2}{|c|}{$\begin{array}{c}\text { Model } 4 . a \\
\text { Fixed Effects }\end{array}$}} & \multirow{2}{*}{\multicolumn{2}{|c|}{$\begin{array}{c}\text { Model } 4 . b \\
\text { Random Effects }\end{array}$}} \\
\hline & & & & & & & & & \\
\hline & & (1) & (2) & (3) & (4) & (5) & (6) & (7) & (8) \\
\hline H1 & Electoral Rule Dummy $(\mathrm{FPTP}=1)$ & $\begin{array}{c}-1.260 \\
(0.287)\end{array}$ & $-\because-$ & $\begin{array}{l}-0.496 \\
(0.172)\end{array}$ & $-\because-$ & $\begin{array}{l}-1.922 \\
(0.337)\end{array}$ &.-- & $\begin{array}{l}-0.671 \\
(0.341)\end{array}$ &.-- \\
\hline H1 & Electoral Rule Disproportionality $(n)$ &.-- & $\begin{array}{l}-0.368 \\
(0.164)\end{array}$ &.-- & $\begin{array}{l}-0.176 \\
(0.083)\end{array}$ &.-- & $\begin{array}{c}-0.626 \\
(0.178)\end{array}$ &.-- & $\begin{array}{l}-0.366 \\
(0.119)\end{array}$ \\
\hline \multirow[t]{6}{*}{ H2 } & Log Effective Number of Parties & $\begin{array}{c}0.218 \\
(0.654)\end{array}$ & $\begin{array}{c}0.307 \\
(0.663)\end{array}$ & $\begin{array}{r}0.781 \\
(0.306)\end{array}$ & $\begin{array}{c}0.834 \\
(0.360)\end{array}$ & $\begin{array}{l}1.116 \\
(0.590)\end{array}$ & $\begin{array}{r}1.207 \\
(0.584)\end{array}$ & $\begin{array}{c}2.412 \\
(0.439)\end{array}$ & $\begin{array}{c}2.227 \\
(0.398)\end{array}$ \\
\hline & Random effects & $x$ & $x$ & $\checkmark$ & $\checkmark$ & $x$ & $x$ & $\checkmark$ & $\checkmark$ \\
\hline & Country fixed effects & $\checkmark$ & $\checkmark$ & $x$ & $x$ & $\checkmark$ & $\checkmark$ & $x$ & $x$ \\
\hline & Year dummies & $\checkmark$ & $\checkmark$ & $\checkmark$ & $\checkmark$ & $\checkmark$ & $\checkmark$ & $\checkmark$ & $\checkmark$ \\
\hline & Other institutional controls & Yes & Yes & Yes & Yes & Yes & Yes & Yes & Yes \\
\hline & $\begin{array}{l}R^{\wedge} 2 \\
\text { Obs. }(N)\end{array}$ & $\begin{array}{c}0.424 \\
237\end{array}$ & $\begin{array}{c}0.414 \\
237\end{array}$ & $\begin{array}{c}0.320 \\
237\end{array}$ & $\begin{array}{r}0.310 \\
237\end{array}$ & $\begin{array}{c}0.644 \\
237\end{array}$ & $\begin{array}{c}0.638 \\
237\end{array}$ & $\begin{array}{c}0.512 \\
237\end{array}$ & $\begin{array}{r}0.525 \\
237\end{array}$ \\
\hline
\end{tabular}

Robust standard errors clustered at the country level reported in parentheses. Other institutional controls include: a (dummy) variable indicating strong coalition habits and its interaction with ENP, the number of parties participating in government, the type of political regime (presidentialism or parliamentarianism), the degree of institutional constraints (a categorical variable taking values from $0-6$ ), years of consolidated democracy, a (dummy) variable indicating government change and the ideological distance between current and previous government. Missing institutional data: all countries from 1960 to 1980 . 
TABLE 3: ELECTORAL RULE TRANSITIONS IN GREECE (1974-2004), NEW ZEALAND (1960-2005) AND ITALY (1963-2001)

\begin{tabular}{|c|c|c|c|c|c|c|c|}
\hline \multirow[b]{2}{*}{ Episodes } & \multirow[b]{2}{*}{ Periods } & Electoral Rule & \multirow[t]{2}{*}{ Transition Type } & \multirow[t]{2}{*}{$\begin{array}{c}\text { Polarization } \\
\text { (Period mean) }\end{array}$} & \multirow[t]{2}{*}{ Difference in Means } & \multirow[t]{2}{*}{ Obs. (N) } & \multirow[t]{2}{*}{ Election Years } \\
\hline & & & & & & & \\
\hline \multicolumn{8}{|c|}{ A. GREECE } \\
\hline \multirow[t]{2}{*}{ I. } & Pre-1989 & Reinforced PR & \multirow[b]{2}{*}{ Proportional } & 2.22 & \multirow{2}{*}{$\begin{array}{c}0.91 \\
(0.34)\end{array}$} & 4 & $1974,1977,1981,1985$ \\
\hline & Post-1989 & PR (D'Hondt hybrid) & & 3.13 & & 3 & $1989 a, 1989 b, 1990$ \\
\hline \multirow[t]{2}{*}{ II. } & Pre-1993 & PR (D'Hondt hybrid) & \multirow[b]{2}{*}{ Majoritarian } & 3.13 & \multirow{2}{*}{$\begin{array}{l}-1.30 \\
(0.31)\end{array}$} & 3 & 1989, 1989b, 1990 \\
\hline & Post-1993 & Majority Premium & & 1.83 & & 4 & 1993, 1996, 2000, 2004 \\
\hline \multicolumn{8}{|c|}{ B. NEW ZEALAND } \\
\hline \multirow[t]{2}{*}{ I. } & Pre-1994 & $\begin{array}{l}\text { First-Past-the-Post } \\
\text { (FPTP) }\end{array}$ & \multirow[t]{2}{*}{ Proportional } & 1.40 & \multirow[t]{2}{*}{$\begin{array}{l}2.17 \\
(0.20)\end{array}$} & 12 & $\begin{array}{c}1960,-63,-66,-69,-72,-75 \\
-78,-81,-84,-87,-90,-93\end{array}$ \\
\hline & Post-1994 & Mixed Member PR & & 3.57 & & 4 & $1996,1999,2002,2005$ \\
\hline \multicolumn{8}{|l|}{ C. ITALY } \\
\hline \multirow[t]{2}{*}{ I. } & Pre-1993 & PR & \multirow[t]{2}{*}{ Majoritarian } & 2.31 & $\begin{array}{l}-0.80 \\
(0.35)\end{array}$ & 8 & $\begin{array}{c}1963,-68,-72,-76,-79,-83 \\
-87,-92\end{array}$ \\
\hline & Post-1993 & Mixed & & 1.51 & & 3 & 1994, 1996, 2001 \\
\hline
\end{tabular}

Standard errors are reported in parentheses. 


\section{References}

Abney, Ronni, Andrea Morrison, and Gary Stradiotto. 2007. "The stability of representation: A cross-national study of party policy dispersion." Representation 43: 151-165.

Adams, James and Samuel Merrill. 2006. "Why small, centrist third parties motivate policy divergence by major parties." American Political Science Review 100: 403-417.

Adams, James, Samuel Merrill, and Bernard Grofman. 2005. A unified theory of party competition: A cross-national analysis integrating spatial and behavioral factors. Cambridge: Cambridge University Press.

Andrews, Josephine T. and Jeannette Money. 2009. "The spatial structure of party competition: Party dispersion within a finite policy space." British Journal of Political Science 39: 805-824.

Armingeon, Klaus, Panajotis Potolidis, Marlène Gerber, and Philipp Leimgruber. 2010. Comparative Political Data Set I (CPDS I), 1960-200\%. Bern: Institute of Political Science, University of Bern.

Austen-Smith, David. 2000. "Redistributing income under proportional representation." Journal of Political Economy 108: 1235-1269.

Austen-Smith, David and James Banks. 1988. "Elections, coalitions, and legislative outcomes." American Political Science Review 82: 405-422.

Baron, David P. and Daniel Diermeier. 2001. "Elections, governments, and parliaments in proportional representation systems." Quarterly Journal of Economics 116: 933-967.

Baron, David P., Daniel Diermeier, and Pohan Fong. 2012. "A dynamic theory of parliamentary democracy." Economic Theory 49: 703-738.

Becher, Michael. 2014. "Endogenous credible commitment and party competition over redistribution under alternative electoral institutions." Meetings of the American Political Science Association, available at http://www.unikonstanz.de/mbecher/pdfs/Commitment.pdf.

Budge, Ian and Michael D. McDonald. 2006. "Choices parties define: Policy alternatives in representative elections, 17 countries 1945-1998." Party Politics 12: 451-466.

Calvert, Randall L. 1985. "Robustness of the multidimensional voting model: Candidate motivations, uncertainty, and convergence." American Journal of Political Science 29: 69-95.

Calvo, Ernesto and Timothy Hellwig. 2011. "Centripetal and centrifugal incentives under different electoral systems." American Journal of Political Science 55: 27-41.

Carey, John M. and Simon Hix. 2011. "The electoral sweet spot: Low-magnitude proportional electoral systems." American Journal of Political Science 55: 383-397. 
Casamatta, Georges and Philippe De Donder. 2005. "On the influence of extreme parties in electoral competition with policy-motivated candidates." Social Choice and Welfare 25: 1-29.

Cho, Seok-Ju. 2014. "Voting equilibria under proportional representation." American Political Science Review 108: 281-296.

Clark, Tom S. and Drew A. Linzer. 2015. "Should I use fixed or random effects?" Political Science Research and Methods 3: 399-408.

Cox, Gary W. 1990. "Centripetal and centrifugal incentives in electoral systems." American Journal of Political Science 34: 903-935.

Curini, Luigi and Airo Hino. 2012. "Missing links in party-system polarization: How institutions and voters matter." Journal of Politics 74: 460-473.

Dalton, Rusell J. 2008. "The quantity and the quality of party systems party system polarization, its measurement, and its consequences." Comparative Political Studies 41: 899-920.

De Sinopoli, Francesco and Giovanna Iannantuoni. 2007. "A spatial voting model where proportional rule leads to two-party equilibria." International Journal of Game Theory 35: 267-286.

De Sinopoli, Francesco and Giovanna Iannantuoni. 2008. "Extreme voting under proportional representation: The multidimensional case." Social Choice and Welfare 30: $401-417$.

DellaVigna, Stefano and Ethan Kaplan. 2007. "The Fox news effect: Media bias and voting." Quarterly Journal of Economics 122: 1187-1234.

Dellis, Arnaud. 2013. "The two-party system under alternative voting procedures." Social Choice and Welfare 40: 263-284.

Dellis, Arnaud and Mandar Oak. 2007. Policy convergence under approval and plurality voting: the role of policy commitment. Social Choice and Welfare 29: 229-245.

Dellis, Arnaud and Mandar Oak. 2015. "Multiple votes, multiple candidacies and polarization." Social Choice and Welfare, Forthcoming.

Dhillon, Amrita and Ben Lockwood. 2002. "Multiple equilibria in the citizen-candidate model of representative democracy." Journal of Public Economic Theory 4: 171-184.

Dow, Jay K. 2001. "A comparative spatial analysis of majoritarian and proportional elections." Electoral Studies 20: 109-125.

Dow, Jay K. 2011. "Party-system extremism in majoritarian and proportional electoral systems." British Journal of Political Science 41: 341-361.

Duverger, Maurice. 1954. Political parties. Trans. Barbara North and Robert North. New York: Wiley. 
Ergun, Selim Jurgen. 2013. "From plurality rule to proportional representation." Economics of Governance 75: 743-756.

Esteban, Joan and Gerald Schneider. 2008. "Polarization and conflict: theoretical and empirical issues." Journal of Peace Research 45: 131-141.

Ezrow, Lawrence. 2008. "Parties' policy programmes and the dog that didn't bark: No evidence that proportional systems promote extreme party positioning." British Journal of Political Science 38: 479-497.

Faravelli, Marco and Santiago Sanchez-Pages. 2014. "(Don't) Make my vote count." Journal of Theoretical Politics, first published on November 11, 2014 as doi:10.1177/0951629814556174.

Frye, Timothy. 2002. "The perils of polarization: Economic performance in the postcommunist world." World Politics 54: 308-337.

Funk, Patricia and Christina Gathmann. 2013. "How do electoral systems affect fiscal policy? Evidence from cantonal parliaments, 1890-2000." Journal of the European Economic Association 11: 1178-1203.

Gallagher, Michael. 1991. "Proportionality, disproportionality and electoral systems." Electoral studies 10: 33-51.

Gerber, Anke and Ignacio Ortuño-Ortín. 1998. "Political compromise and endogenous formation of coalitions." Social Choice and Welfare 15: 445-454.

Green, Jane. 2007. "When voters and parties agree: Valence issues and party competition." Political Studies 55: 629-655.

Grofman, Bernard. 1983. "Measures of bias and proportionality in seats-votes relationships." Political Methodology 9: 295-327.

Groseclose, Timothy. 2001. "A model of candidate location when one candidate has a valence advantage." American Journal of Political Science 45: 862-886.

Grosser, Jens and Thomas R. Palfrey. 2013. "Candidate entry and political polarization: An antimedian voter theorem." American Journal of Political Science 58: 127-143.

Herrera, Helios, Massimo Morelli, and Salvatore Nunnari. 2014. "Turnout across democracies." National Bureau of Economic Research Working Paper No. 20451.

Herrera, Helios, Massimo Morelli, and Thomas R. Palfrey. 2014. "Turnout and power sharing." Economic Journal 124: F131-F162.

Huber, John D. and G. Bingham Powell. 1994. "Congruence between citizens and policymakers in two visions of liberal democracy." World Politics 46: 291-326.

Iaryczower, Matias and Andrea Mattozzi. 2013. "On the nature of competition in alternative electoral systems." Journal of Politics 71: 829-853. 
Indridason, Indridi H. 2011. "Proportional representation, majoritarian legislatures, and coalitional voting." American Journal of Political Science 55: 955-971.

Iversen, Torben and David Soskice. 2006. "Electoral institutions and the politics of coalitions: Why some democracies redistribute more than others." American Political Science Review 100: 165-181.

King, Gary. 1990. "Electoral responsiveness and partisan bias in multiparty democracies." Legislative Studies Quarterly 15: 159-181.

Laakso, Markku and Rein Taagepera. 1979. "Effective number of parties: A measure with application to West Europe." Comparative Political Studies 12: 3-27.

Lijphart, Arend. 1984. Democracies: Patterns of majoritarian and consensus government in twenty-one countries. Yale University Press.

Lin, Tse-Min, James M. Enelow, and Han Dorussen. 1999. "Equilibrium in multicandidate probabilistic spatial voting." Public Choice 98: 59-82.

Lizzeri, Alessandro and Nicola Persico. 2001. "The provision of public goods under alternative electoral incentives." American Economic Review 91: 225-239.

Llavador, Humberto. 2006. "Electoral platforms, implemented policies, and abstention." Social Choice and Welfare 27: 55-81.

Matakos, Konstantinos, Orestis Troumpounis, and Dimitrios Xefteris. 2013. "Electoral Rule Disproportionality and Platform Polarization." EPSA 2013 Annual General Conference Paper 809. Available at SSRN: http://ssrn.com/abstract=2225152.

Merrill, Samuel and James Adams. 2007. "The effects of alternative power-sharing arrangements: Do "moderating" institutions moderate party strategies and government policy outputs?" Public Choice 131: 413-434.

Morelli, Massimo. 2004. "Party formation and policy outcomes under different electoral systems." Review of Economic Studies 71: 829-853.

Myerson, Roger B. 1993a. "Effectiveness of electoral systems for reducing government corruption: a game-theoretic analysis." Games and Economic Behavior 5: 118-132.

Myerson, Roger B. 1993b. "Incentives to cultivate favored minorities under alternative electoral systems." American Political Science Review 87: 856-869.

Ortuño-Ortín, Ignacio. 1997. "A spatial model of political competition and proportional representation." Social Choice and Welfare 14 427-438.

Osborne, Martin J. and Al Slivinski. 1996. "A model of political competition with citizencandidates." Quarterly Journal of Economics 111: 65-96.

Persson, Torsten, Guido Tabellini, and Francesco Trebbi. 2003. "Electoral rules and corruption." Journal of the European Economic Association 1: 958-989. 
Roemer, John E. 1994. "A theory of policy differentiation in single issue electoral politics." Social Choice and Welfare 11: 355-380.

Saporiti, Alejandro. 2014. "Power sharing and electoral equilibrium." Economic Theory 55: $705-729$.

Sartori, Giovanni. 1976. Parties and Party Systems. Cambridge: Cambridge University Press.

Taagepera, Rein. 1986. "Reformulating the cube law for proportional representation elections." American Political Science Review 80: 489-504.

Theil, Henry. 1969. "The desired political entropy." American Political Science Review 63: $521-525$.

Tsebelis, George. 2002. Veto players: How political institutions work. Princeton NJ: Princeton University Press.

Tullock, Gordon. 1980. "Efficient rent seeking." In Toward a Theory of the Rent-Seeking Society, eds. James M. Buchanan, Robert D. Tollison, and Gordon Tullock, College Station, TX: Texas A\&M University Press, 97-112.

Volkens, Andrea, Onawa Lacewell, Pola Lehmann, Sven Regel, Henrike Schultze, and Annika Werner. 2012. The manifesto data collection. Manifesto Project (MRG/CMP/MARPOR), Berlin: Wissenschaftszentrum Berlin für Sozialforschung (WZB).

Warwick, Paul. 1994. Government survival in parliamentary democracies. Cambridge: Cambridge University Press.

Wittman, Donald. 1977. "Candidates with policy preferences: A dynamic model." Journal of Economic Theory 14: 180-189. 